\title{
Subsequently $90^{\circ}$ Repositioned Triple E Shaped Microstrip Patch Antenna Design for Multiband Application
}

\author{
Razin Ahmed \\ Islamic University of \\ Technology (IUT) \\ Gazipur- 1704
}

\author{
Shahriar Rahman \\ American International \\ University Bangladesh (AIUB) \\ Banani, Dhaka
}

\author{
Tanver Ahmed \\ American International \\ University-Bangladesh (AIUB) \\ Banani, Dhaka
}

\begin{abstract}
Wireless communication system and technology opened a new horizon around the world through electromagnetic spectrum. As the technology evolving demand for high and continuous data connectivity in satellite and radar communication has been growing faster, researchers are facing challenges to integrate cost efficient, miniature size and multiband operating antenna in wireless devices. Microstrip Patch Antenna can fulfill all requirements but there is always a trade-off between the performance and design. In this paper modified slots with reconfigured E shapes Microstrip Patch antenna is designed and analyzed for multiband wireless application. The probe feeding technique and design structure provides the antenna to operate in five different frequencies. The antenna resonates at $7.81 \mathrm{GHz}$ in $\mathrm{C}$ band, $8.31 \mathrm{GHz}, 9.65$ $\mathrm{GHz}$ and $11.86 \mathrm{GHz}$ in $\mathrm{X}$ band, and $13.2 \mathrm{GHz}$ and $14.79 \mathrm{GHz}$ in $\mathrm{Ku}$ band with return loss of $-19.26 \mathrm{~dB},-24.82 \mathrm{~dB},-13.18$ $\mathrm{dB},-33.61 \mathrm{~dB},-12.46 \mathrm{~dB}$ and $-12.04 \mathrm{~dB}$ respectively of proposed antenna have been examined and discussed.
\end{abstract}

\section{Keywords}

Microstrip Patch Antenna (MPA), Rectangular Microstrip Patch Antenna (RMPA), Electromagnetic (EM),

\section{INTRODUCTION}

The contemporary theory of electromagnetic wave properties has come from one of the greatest pioneer in history Science: James Clerk Maxwell. His famous equations enabled us to take leaps in the field of electromagnetism resulting wireless technology to grow exponentially over decades to come. Numerous ranges of frequency band for diverse communication system are present in the modern time and are allocated to use in various purposes. Therefore integration of multiband"e in wireless communication devices became more dependable in most social, scientific, commercial and other contexts. To enable multiband operation, antenna should have the option to transmit and receive multiple frequencies. Among all the different types of antennas [1 \& 2], Microstrip Patch Antenna (MPA) has become well accepted around the world. The fundamental structure is made up of a conducting patch of any non-planar or planar geometry on one side of a dielectric substrate and a ground plane on other side [3]. It has higher multilateral lead for planer profile, capacity to function in microwave frequency range, economic to manufacture and simple to construct in integrated circuit technology when contrasted with conventional antenna. Due to their light weight, low volume and low fabrication cost, they can be produced in huge quantities [4-6].

However beside all advantages of MPA there are disadvantages also such as low efficiency, single frequency operation and narrow impendence bandwidth. In recent years, several scientists from industries and universities are investigating and have come up with several multiband antenna techniques, among them are loading the patch with shorting pins [7-9], using two feeding ports [10], loading slits [11], using stacked patches [12-15], PIN diodes, switches and varactor diodes have been used. Major shortcoming of the design is the requirement for controlling turn ON/OFF switch for reconfigurable frequency operations [16-18] using slots in the patch [19 \& 20]. Many structures like Square Slot, U-Slot, T-Slot, V-Slot and many other shapes are incorporated into the patch of antenna. Now, to improve impedance bandwidth some techniques may be applied such as increasing the substrate thickness [21], covering the patch by additional dielectric layers [22 \& 23], introducing parasitic element either in coplanar or in multilayer configuration [24], and performing slots in radiator patch [25]. The slots help to perturb the surface current path on the patch that generates local inductive effect which is responsible for multiband operation. Among all the approach slot technique is very promising because it can provide excellent bandwidth improvement and maintain a single-layer radiating structure with multiband feature. From above literature authors are motivated to design an MPA which operates in multiband application.

\section{ANTENNA DESIGN}

The antenna configuration has been made on the conventional Rectangular Microstrip Patch Antenna (RMPA). The whole design of the proposed antenna is developed in IE3D EM simulator software using low cost FR4 substrate material of thickness $\mathrm{h}=1.6 \mathrm{~mm}$ and permittivity $\mathcal{E}_{r}=4.31$. The antenna consists of radiating patch, ground plane and dielectric substrate between them. Figure 1 represents the basic structure of proposed antenna. The initial parameters are determined from the following equation [26].

$$
\begin{aligned}
& W=\frac{v_{o}}{2 f_{r}} \sqrt{\frac{2}{\varepsilon_{r}+1}} \\
& \varepsilon_{\text {eff }}=\frac{\varepsilon_{r}+1}{2}+\frac{\varepsilon_{r}-1}{2}\left[1+12 \frac{h}{W}\right]^{\frac{-1}{2}} \\
& \Delta L=0.421 h \frac{\left(\varepsilon_{e f f}+0.3\right)\left(\frac{W}{h}+0.264\right)}{\left(\varepsilon_{e f f}-0.258\right)\left(\frac{W}{h}+0.8\right)}
\end{aligned}
$$




$$
L=\frac{1}{2 f_{r} \sqrt{\varepsilon_{\text {eff }}} \sqrt{\mu_{o} \varepsilon_{o}}}-2 \Delta L
$$

Here $\mathrm{W}$ is the width of the patch, $\mathrm{v}_{\mathrm{o}}$ is the speed of light in a vacuum, $\varepsilon_{\mathrm{r}}$ is the dielectric constant of the substrate, $\mathrm{f}_{\mathrm{r}}$ is the target frequency, $\varepsilon_{\text {eff }}$ is the effective dielectric constant of the substrate, $\Delta \mathrm{L}$ represents the extension in length caused by the fringing effect, $h$ is the thickness of the substrate and $\mathrm{L}$ is the length of the patch.

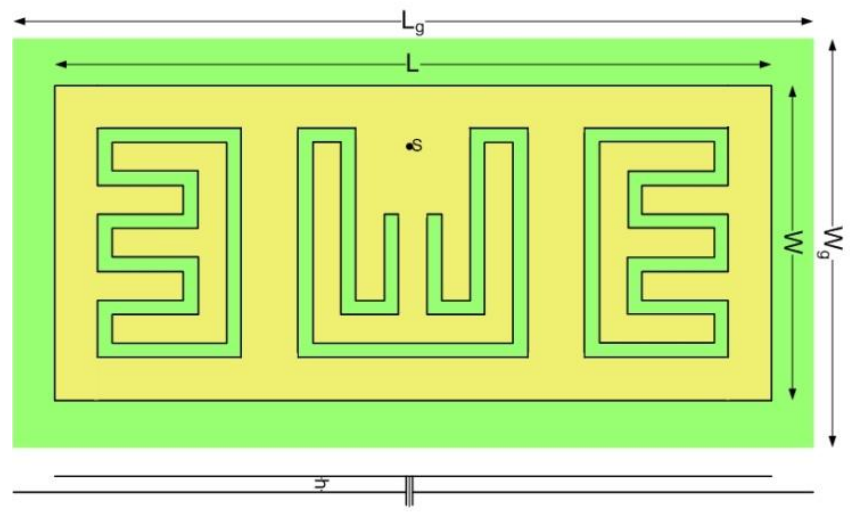

Fig 1: Design of Proposed antenna

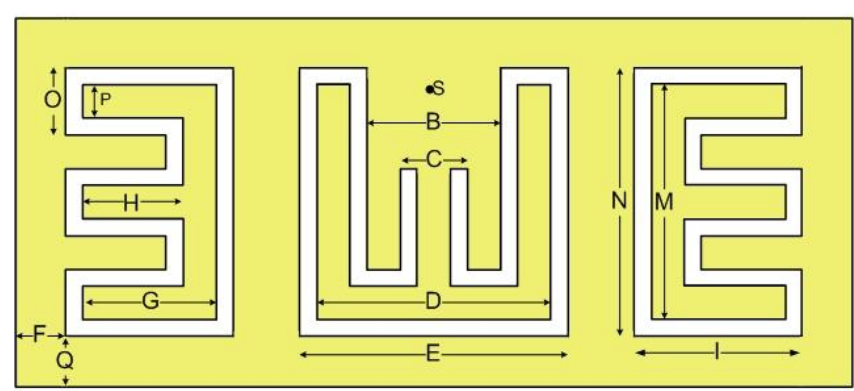

Fig 2: Radiating patch of proposed antenna

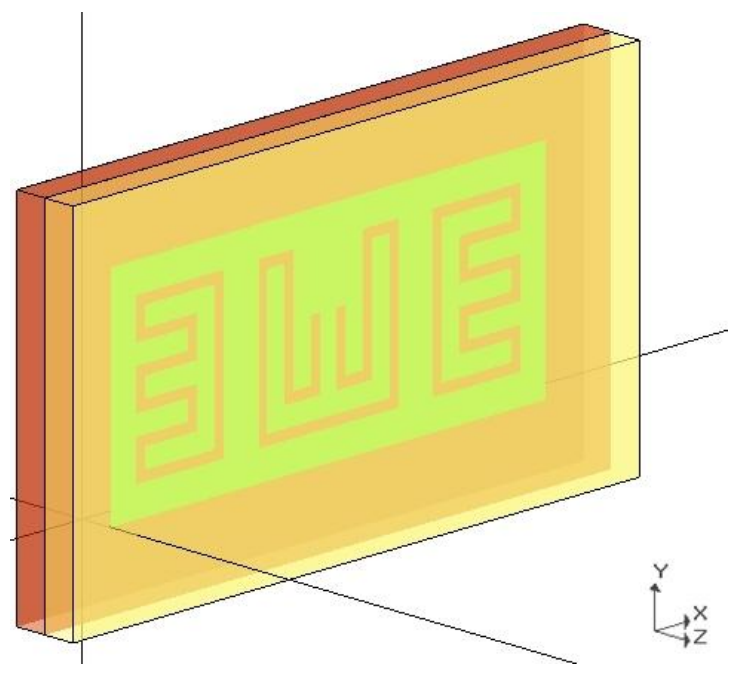

Fig 3: 3D view of proposed antenna

The RMPA and proposed antenna both have patch and ground plane dimension of $(\mathrm{LxW}) 25 \mathrm{~mm} \times 11 \mathrm{~mm}$ and $\left(\mathrm{L}_{\mathrm{g}} \mathrm{xW}\right)$ $35 \mathrm{~mm} \times 21 \mathrm{~mm}$ respectively. For proposed antenna three modified slots have been cutoff from the rectangular patch to interrupt the surface current on the patch so that local inductive effect occurs which is responsible for multiband attribute. The slots are trimmed off in precise manner so that 180,270 and 0 degrees phase shift of capital alphabet "E" shape copper plate can be plot into the slots without any attachment to the main patch. In Figure 2 slots dimensions are illustrated through Table 1. Extra another substrate layer has been fastened on the main slotted patch with same dielectric constant of 4.31 as the substrate of proposed antenna in between patch and ground plane, shown in Figure 3. It has been done to increase the bandwidth of the overall antenna and improve other antenna characteristics.

Table 1. Dimension of Proposed Antenna

\begin{tabular}{|c|c|}
\hline Parameters & Dimensions (mm) \\
\hline $\mathrm{B}$ & 4.2 \\
\hline $\mathrm{C}$ & 2.2 \\
\hline $\mathrm{D}$ & 7 \\
\hline $\mathrm{E}$ & 8 \\
\hline $\mathrm{F}$ & 1.5 \\
\hline G & 4 \\
\hline $\mathrm{H}$ & 3 \\
\hline I & 5 \\
\hline M & 7 \\
\hline $\mathrm{N}$ & 8 \\
\hline $\mathrm{O}$ & 2 \\
\hline $\mathrm{P}$ & 1 \\
\hline Q & 1.5 \\
\hline $\mathrm{L}$ & 25 \\
\hline $\mathrm{W}$ & 11 \\
\hline $\mathrm{L}_{\mathrm{g}}$ & 35 \\
\hline $\mathrm{W}_{\mathrm{g}}$ & 21 \\
\hline
\end{tabular}

\section{SIMULATION AND RESULT}

The software IE3D is an integrated full wave EM simulator which has optimization package for analysis and design of 3D and planar microwave circuits. It provides accurate and precise result in antenna designing and simulation. The antenna dimensions are transferred to the software for analysis. Figure 4 represent the RMPA performance in terms of return loss and frequencies. The conventional RMPA resonates at $11.26 \mathrm{GHz}$ and $13.37 \mathrm{GHz}$ with return loss of $18.29 \mathrm{~dB}$ and $-20.27 \mathrm{~dB}$ respectively. The feeding position and technique provides the antenna to operate in $\mathrm{X}$ and $\mathrm{Ku}$ band. The bandwidth of the operating frequencies is noted after $-10 \mathrm{~dB}$ critically which are $163 \mathrm{MHz}$ and $250 \mathrm{MHz}$ respectively. 


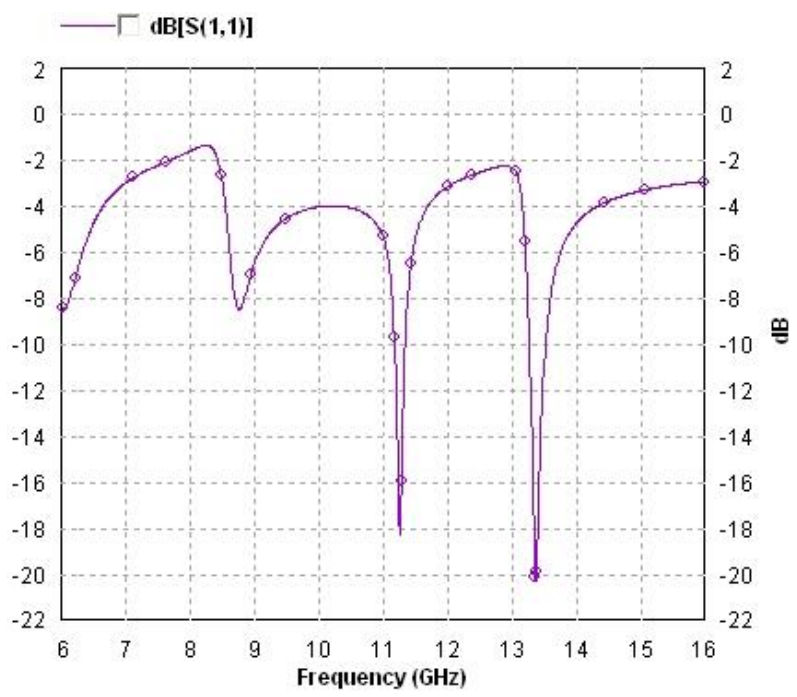

Fig 4: Reflection coefficient of RMPA

Figure 5 illustrates the reflection coefficient of the proposed antenna. It has been observed that the antenna operates in six different frequencies under $\mathrm{C}, \mathrm{X}$, and $\mathrm{Ku}$ band. The resonant frequencies are $7.81 \mathrm{GHz}, 8.31 \mathrm{GHz}, 9.65 \mathrm{GHz}, 11.86 \mathrm{GHz}$, $13.2 \mathrm{GHz}$ and $14.79 \mathrm{GHz}$ with return loss of $-19.26 \mathrm{~dB},-24.82$ $\mathrm{dB},-13.18 \mathrm{~dB},-33.61 \mathrm{~dB},-12.46 \mathrm{~dB}$ and $-12.04 \mathrm{~dB}$ respectively. The bandwidth of the operating frequencies are $564 \mathrm{MHz}$ for first and second, $1.20 \mathrm{GHz}$ for third, $1.86 \mathrm{GHz}$ for forth and fifth, $284 \mathrm{MHz}$ for sixth resonant frequency. Figure 6 represents VSWR of proposed antenna where it has been observed that the ratio of the maximum voltage of a standing wave pattern on a transmission line to the minimum voltage on the line is less than 2 at operating frequencies

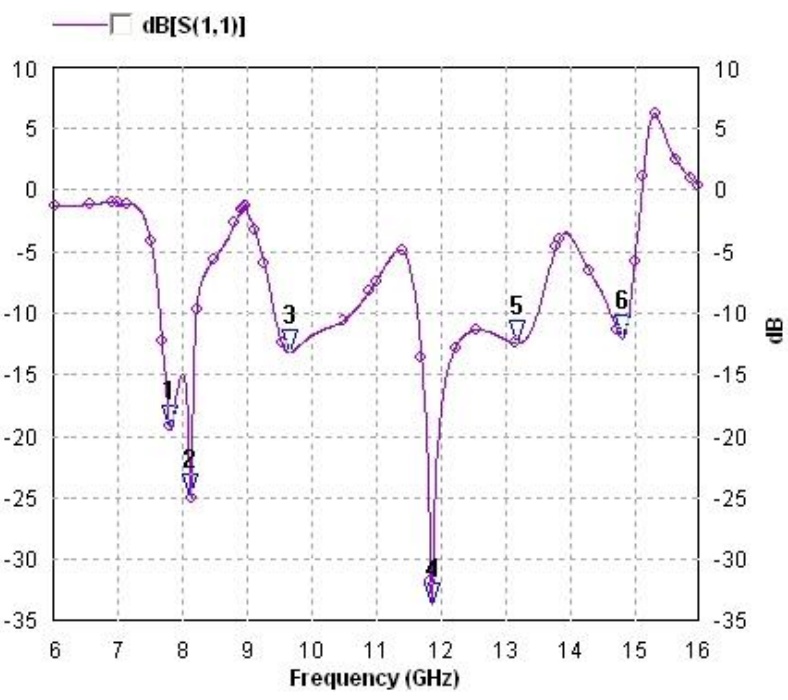

Fig 5: Reflection coefficient of Proposed Antenna

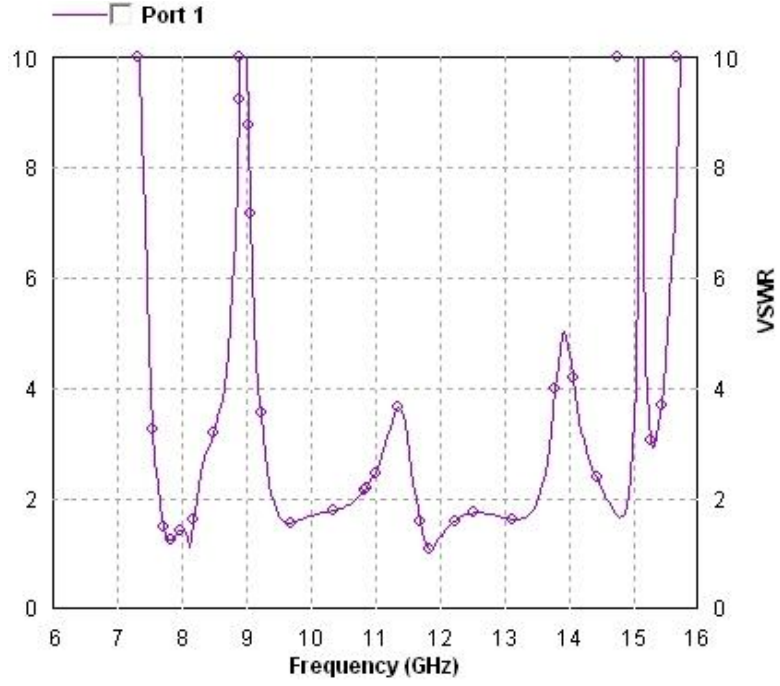

Fig 6: VSWR of Proposed Antenna

Figure 7 shows the comparison of RMPA and proposed antenna under same graph respect to reflection coefficient. From the diagram it is cleared that proposed antenna has better performance than RMPA. Proposed antenna has six resonant frequencies and the bandwidth covers $8.3 \%$ of $\mathrm{C}$, $45 \%$ of $\mathrm{X}$ and $30 \%$ of $\mathrm{Ku}$ band, where as RMPA has only two resonant frequencies and the bandwidth covers $4 \%$ of $X$ and $6 \%$ of $\mathrm{Ku}$ band. The extra layer of substrate on the top of patch enhances the performance of proposed antenna

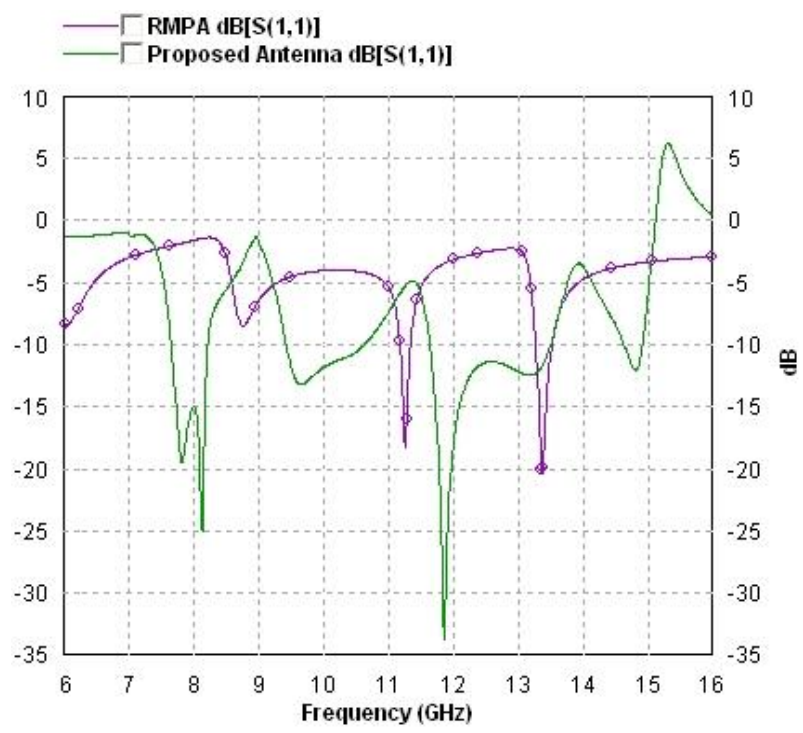

Fig 7: Comparison of RMPA vs Proposed Antenna

Figure 8-13 shows 2D directional radiation pattern of proposed antenna. Higher directivity implies a more focused antenna.At operating frequencies the directivities are 7.44 $\mathrm{dBi}, 6.67 \mathrm{dBi}, 7.44 \mathrm{dBi}, 8.02 \mathrm{dBi}, 6.66 \mathrm{dBi}$, and $7.01 \mathrm{dBi}$ respectively. The figure shown below for the elevation pattern from $\varphi=0$ and $\varphi=90$ degrees. 


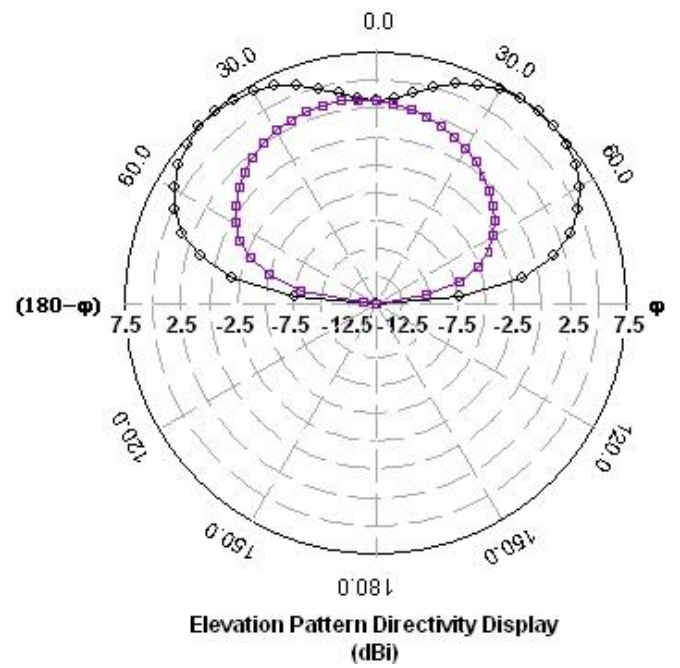

Fig 8: Directivity at 7.81 GHz of Proposed Antenna

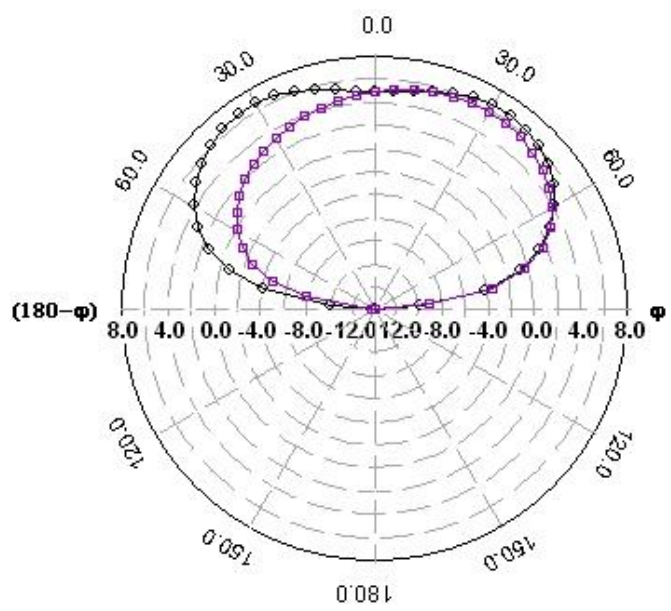

Elevation Pattern Directivity Display

(dBi)

Fig 9: Directivity at 8.13 GHz of Proposed Antenna

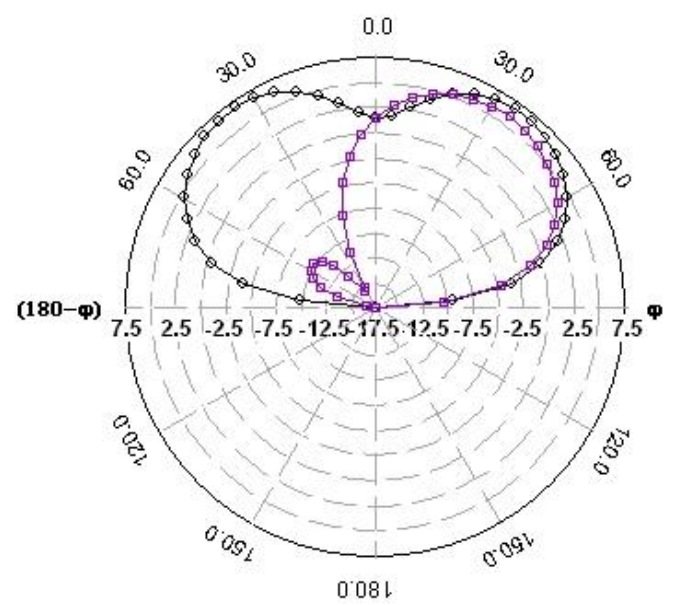

Elevation Pattern Directivity Display

(dBi)

Fig 10: Directivity at 9.65 GHz of Proposed Antenna

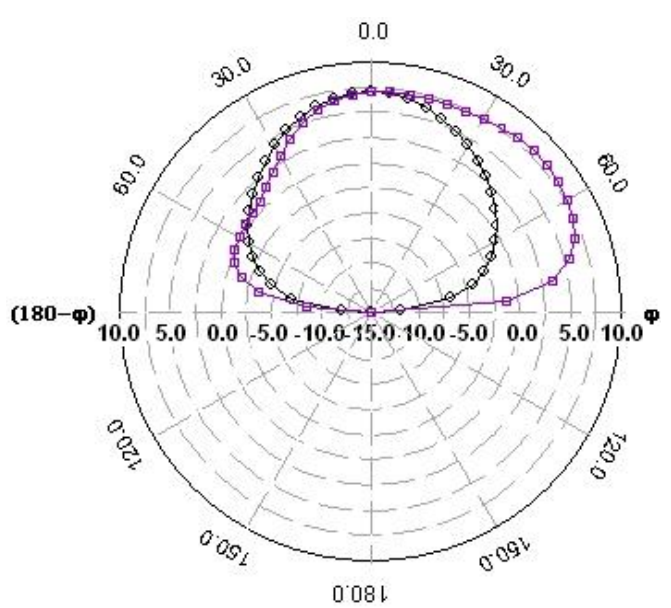

Elevation Pattern Directivity Display (dBi)

Fig 11: Directivity at 11.86 GHz of Proposed Antenna

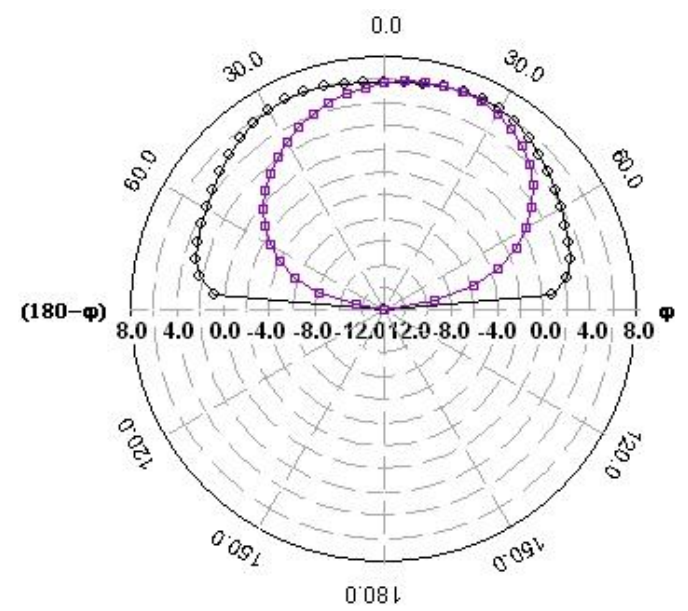

Elevation Pattern Directivity Display

(dBi)

Fig 12: Directivity at 13.20 GHz of Proposed Antenna

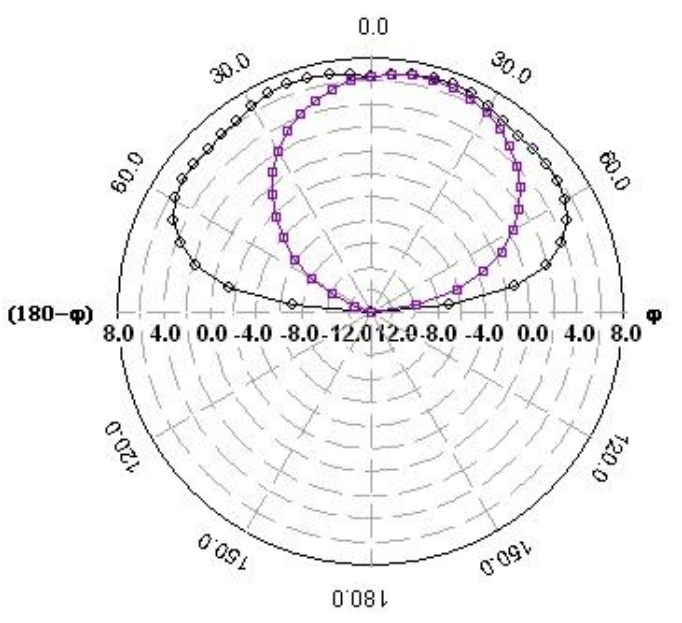

Elevation Pattern Directivity Display (dBi)

Fig 13: Directivity at 14.79 GHz of Proposed Antenna 


\section{CONCLUSION}

Due to extensive use in handheld devices, Micro strip antennas have become a fast emergent area of investigation. The potentiality of this particular genre of antenna is infinite; thanks to the light weight and compact structure and easy fabrication facility. In this paper an innovative design with subsequent $90^{\circ}$ repositioned Triple E slot was investigated using is an integrated full wave EM simulator. It was found that the feeding position and the unique technique have provided the antenna to operate in $\mathrm{X}$ and $\mathrm{Ku}(12 \mathrm{GHz})$ band. It was also concluded that the slots help to agitate the surface current path on the patch that generates local inductive effect which is responsible for multiband operation. We find this design very helpful for inter-galaxy and inter-satellite communication.

\section{CREDITS}

Our extended gratitude goes to Mr. Rinku Basak for his relentless effort \& guidance which helped us achieve this high performance innovative design.

\section{REFERENCES}

[1] Puente, Borja, Navarro, and Romeu, "An Iterative Model for Fractal Antennas: Application to the Sierpinski Gasket Antenna", IEEE Transactions on Antennas and Propagation, Vol. 48, No. 5, pp 713-719, May 2000.

[2] Z.D. Liu, P.S. Hall, and D. Wake, Dual-frequency planar inverted-F antenna, IEEE Trans Antennas Propagat 45 (1997), 1451-1458.

[3] David M. Pozar, "Microstrip Antennas", Proceedings of IEEE, Vol. 80, No. 1, January 1992.

[4] Ramesh, G., B. Prakash, B. Inder, and I. Apisak, Microstrip Antenna Design Handbook, Artech House, USA, 2001.

[5] James, J. R. and Hall, P. S., "Handbook of Microstrip Antennas" (Peter Peregrinus), Vol. 2, 1989

[6] Constantine A. Balanis, "Antenna Theory: Analysis and Design”, John Wiley \& Sons, 3rd Edition, 2005

[7] C. L. Tang, H. T. Chen, and K. L. Wong, "Small circular Microstrip antenna with dual-frequency operation," IEEE Electron. Lett., vol.33, no. 13, pp. 1112-1113, Jun. 1997.

[8] K. L. Wong and W. S. Chen, "Compact microstrip antenna with dual frequency operation," IEEE Electron. Lett., vol. 33, no. 8, pp. 646-647, Apr. 1997.

[9] S. C. Pan and K. L. Wand, "Dual frequency triangular Microstrip antenna with shorting pin," IEEE Trans. Antennas Propag., vol. 45, pp. 1889-1891, Dec. 1997.

[10] J. F. Zurcher, A. Skrivervik, O. Staub, and S. Vaccaro, "A compact dual-port dual-frequency printed antenna with high decoupling," Microw Opt. Technol. Lett., vol. 19, pp. 131-137, Oct. 1998.

[11] Indra Surjati, "Dual Frequency Operation Triangular Microstrip Antenna Using A Pair Of Slit”, 2005 AsiaPacific Conference on Communications, Perth, Western Australia, pp. 125-127, 3 - 5, October 2005.

[12] L. Zaid, G. Kossiavas, J. Y. Dauvignac, J. Cazajous, and A. Papiemik, "Dual-frequency and broadband antennas with stacked quarter wavelength elements," IEEE Trans. Antennas Propag., vol. 47, no. 4, pp. 654-660, Apr. 1999.
[13] J. S. Dahele, K. F. Lee, and D. P. Wong, "Dual frequency stacked annular ring microstrip antenna," IEEE Trans. Antennas Propag., vol. 35, no. 11, pp. 12811285, Nov. 1987

[14] F. Croq and D. M. Pozar, "Multi-frequency operation on Microstrip antennas using aperture coupled parallel resonators," IEEE Trans. Antennas Propag., vol. 40, no. 11, pp. 1367-1374, Nov. 1992.

[15] J. Wang, R. Fralich, C. Wu, and J. Litva, "Multifunctional aperture coupled stack patch antenna," IEEE Electron. Lett., vol. 26, no. 25, pp. 2067-2068, Dec. 1990.

[16] D. Peroulis, K. Sarabandi and L. B. P. Katehi. 2005. Design of reconfigurable slot antennas. IEEE Trans. Antennas Propag., vol. 53, no.7, pp. 645-654.

[17] H. Okabe and K. Takei. 2001. Tunable antenna system for $1.9 \mathrm{GHz}$ PCS handsets. IEEE Antennas Propag. Int. Symp., vol. 1, pp. 166- 169.

[18] [18] F. Yang and Y. R. Samii. 2002. A reconfigurable patch antenna using switchable slots for circular polarization diversity. IEEE Micro. Wireless Comp. Lett., vol. 12, no. 3, pp. 96-98.

[19] S. Maci, G. B. Gentili, P. Piazzesi, and C. Salvador, "Dual band slot loaded patch antenna," Proc. Inst. Elect. Eng. Microw. Antennas Propag., vol. 142, pp. 225-232, Jun. 1995.

[20] B. F.Wang and Y. T. Lo, "Microstrip antennas for dualfrequency operation," IEEE Trans. Antennas Propag., vol. 32, pp. 938-943, Sep. 1984.

[21] Yang Fan, Y. Rahmat-Samii, "Microstrip antennas integrated with electromagnetic band-gap (EBG) structures: a low mutual coupling design for array applications" IEEE Transactions on Antennas and Propagation, Volume:51 Issue: 10, pp: 2936-2946, Oct. 2003.

[22] N. G. Alexopoulos and D. R. Jackson, "Fundamental superstrate (cover) effects on printed circuit antennas," IEEE Trans. Antennas Propag., vol. AP-32, pp. 807-816, Aug. 1984.

[23] Kim, J., H. Kim, and K. Chun, PPerformance enhancements of a microstrip antenna with multiple layer substrates," International Symposium on Signals, Systems and Electronics 2007 (ISSSE '07), 319\{322, 2007.

[24] K.F. Lee and R.Q Lee, "Microstrip subarray with coplanar and stacked parasitic elements", Electronics Letters, Volume: 26, Issue: 10, 1 May 1990.Transactions on Antennas and Propagation, Volume: 51, Issue: 10, pp: 2936-2946, Oct. 2003.

[25] X.L. Bao, M.J. Ammann, "Small patch/slot antenna with $53 \%$ input impedance bandwidth", Electronics Letters, Volume 43, Issue 3, pp. 146 - 148, Feb 2007.

[26] Razin Ahmed, Md. Fokrul Islam, "E shaped Microstrip Patch Antenna for Ku band" Published in International Journal of Computer Applications Volume 80, No.6, October 2013 